\title{
Annals of Case Reports
}

Case Report

Rizzo R, et al. Ann Case Report 6: 751.

DOI: 10.29011/2574-7754.100751.

\section{Ectopic Liver Nodule in an Infant with Pyloric Stenosis Presentation: First Detailed Case Report of Laparoscopic Resection in a Pediatric Patient}

\author{
Rizzo R ${ }^{1}$, Rousseau $V^{1}$, Berteloot $L^{2}$, Barbet $\mathbf{P}^{3}$, Toubiana $\mathrm{J}^{4}$, Capito $\mathbf{C}^{1}$, Sarnacki $\mathbf{S}^{1}$ \\ ${ }^{1}$ Department of Pediatric Surgery and Urology, Hôpital Necker-Enfants Malades, Assistance Publique-Hôpitaux de Paris, Paris, France \\ ${ }^{2}$ Department of Pediatric Radiology, Hôpital Necker-Enfants Malades, Assistance Publique-Hôpitaux de Paris, Paris, France \\ ${ }^{3}$ Department of Pathology, Hôpital Necker-Enfants Malades, Assistance Publique-Hôpitaux de Paris, Paris, France \\ ${ }^{4}$ Department of Pediatric Emergency, Hôpital Necker-Enfants Malades, Assistance Publique-Hôpitaux de Paris, Paris, France
}

"Corresponding author: Rizzo R, Department of Pediatric Surgery and Urology, Hôpital Necker-Enfants Malades, Assistance Publique-Hôpitaux de Paris, Paris, France.

Citation: Rizzo R, Rousseau V, Berteloot L, Barbet P, Toubiana J. (2021) Ectopic Liver Nodule in an Infant with Pyloric Stenosis Presentation: First Detailed Case Report of Laparoscopic Resection in a Pediatric Patient. Ann Case Report 6: 751. DOI: 10.29011/2574-7754.100751.

Received Date: 24 May, 2021; Accepted Date: 17 August, 2021; Published Date: 23 August, 2021

\section{Introduction}

Ectopic liver represents a rare clinical entity of developmental error [1], which may be rarely symptomatic and does not generally cause a clinical problem, especially in pediatric patients $[2,3]$. It may be found incidentally during laparoscopy, laparotomy or autopsy [7]. In pediatric patients it could be intra-thoracic [46] and associated to congenital diaphragmatic hernia [8-12], but it is seen more frequently in the abdominal cavity [13-16]. We report the first detailed case of laparoscopic resection of ectopic abdominal liver nodule with a pyloric stenosis presentation in an infant.

\section{Case}

A 21-days-old male presented to Emergency Department of our hospital with 1 week history of vomiting after feeds. Vomiting was non projectile, nonbilious, and nonbloody. It was not associated with weight loss, metabolic alkalosis or diarrhea, and there was no history of fever, shortness of breath, or cough. He was born at term by uncomplicated spontaneous vaginal delivery with a birth weight of $4030 \mathrm{~g}$. He was not dysmorphic and his mother's infectious serology was negative at antenatal booking. On physical examination he had no pallor, jaundice or lymphadenopathy, and his vitals signs were normal. He had a soft non distended abdomen and there was no palpable mass in epigastrium. Examination of other system was unremarkable. Arterial blood gas didn't show a metabolic alkalosis and electrolytes were essential normal with standard bicarbonate $26 \mathrm{mmol} / \mathrm{L}$, sodium $136 \mathrm{mmol} / \mathrm{L}$, potassium $4.6 \mathrm{mmol} / \mathrm{L}$, chloride $105 \mathrm{mmol} / \mathrm{L}$ and urea $2.5 \mathrm{mmol} / \mathrm{L}$. The full blood count was normal and CRP was $9 \mathrm{mg} / \mathrm{L}$. Supine abdominal X-rays was normal, and first abdominal ultrasound showed normal position of mesenteric vessels and a thickened pylorus not perfectly visible. A second abdominal ultrasound showed an inflammatory aspect of antro-pyloric region associated with a non-vascularized hypo-echogenic mass [Figure 1]. Upon suspicion of infected duodenal duplication, a double antibiotics therapy were installed for $48 \mathrm{~h}$ with Ceftriaxone $50 \mathrm{mg} / \mathrm{kg} / \mathrm{day}$ and Metronidazole $70 \mathrm{mg} / \mathrm{kg} /$ day. An additional abdominal ultrasound control showed a normal pylorus and was completed by an MRIscan which confirmed the presence of retro-pyloric cystic lesion [Figure 2]. In suspected pyloric or duodenal infected duplication cyst, an explorative laparoscopy was performed. Under general anesthesia the child was placed in a supine anti- Trendelemburg position, a 5-mm optique trocar was placed supra-umbilical, two 3-mm laparoscopic ports were placed on the transverse umbilical line at 2-cm leftward and rightward from the umbilicus, and an accessory 3-mm trocar was placed in epigastrium. The following laparoscopic instruments were used: a fenestrated grasper, a monopolar hook, and a suction instrument. Pneumoperitoneum was achieved with a flow of 2,7 liter per minute and a pressure of $8 \mathrm{mmHg}$. As soon as a complete lysis of the adhesions between the pylorus and the segment 1 of the liver was performed, the lesion was identified as a $1,5-\mathrm{cm}$ necrotic and friable non-vascularized mass developed through the small epiploon. An accurate enucleation of the lesion was completed using monopolar hook and fenestrated grasper. Therefore, an integrity test of the antropyloric gastric wall was performed with a blue integrity test. The mass was finally extracted through the umbilical port thanks to an endobag. No intra-operative complications occurred.

Post-operatively, his recovery was uneventful and he was discharged in 2nd post-operative day, feeding normally. 
Citation: Rizzo R, Rousseau V, Berteloot L, Barbet P, Toubiana J. (2021) Ectopic Liver Nodule in an Infant with Pyloric Stenosis Presentation: First Detailed Case Report of Laparoscopic Resection in a Pediatric Patient. Ann Case Report 6: 751. DOI: 10.29011/2574-7754.100751.

Histopathological findings revealed an heterotopic necrosed liver nodule with centrals veins of hepatic lobule and biliary ducts [Figures 3a-b, 4a-b]. At a 3-months follow up, both clinical visit and ultrasound study did not evidence any issue or late complication.

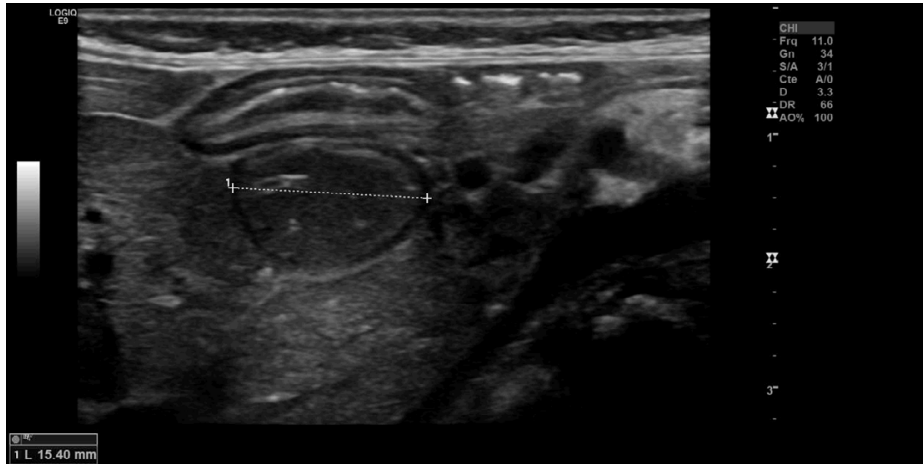

Figure 1: A second abdominal ultrasound showed an inflammatory aspect of antro-pyloric region associated with a non-vascularized hypo-echogenic mass.

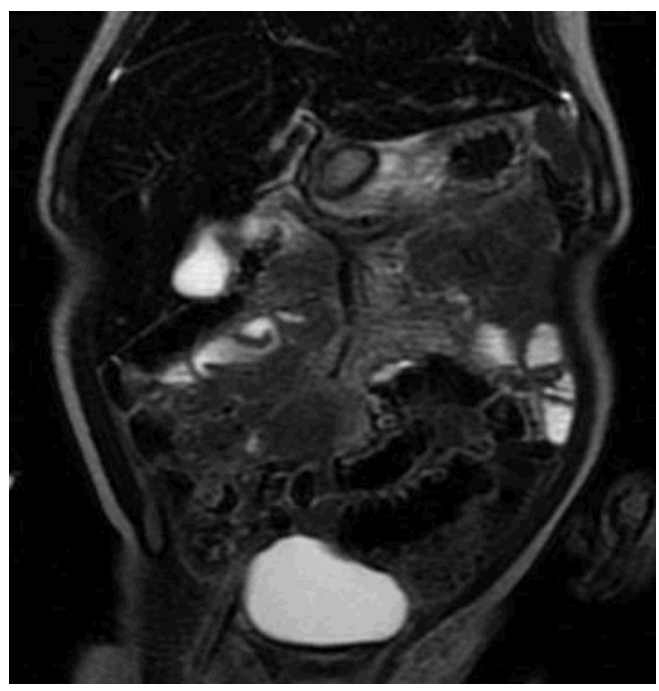

Figure 2: An additional abdominal ultrasound control showed a normal pylorus and was completed by an MRI-scan which confirmed the presence of retro-pyloric cystic lesion.
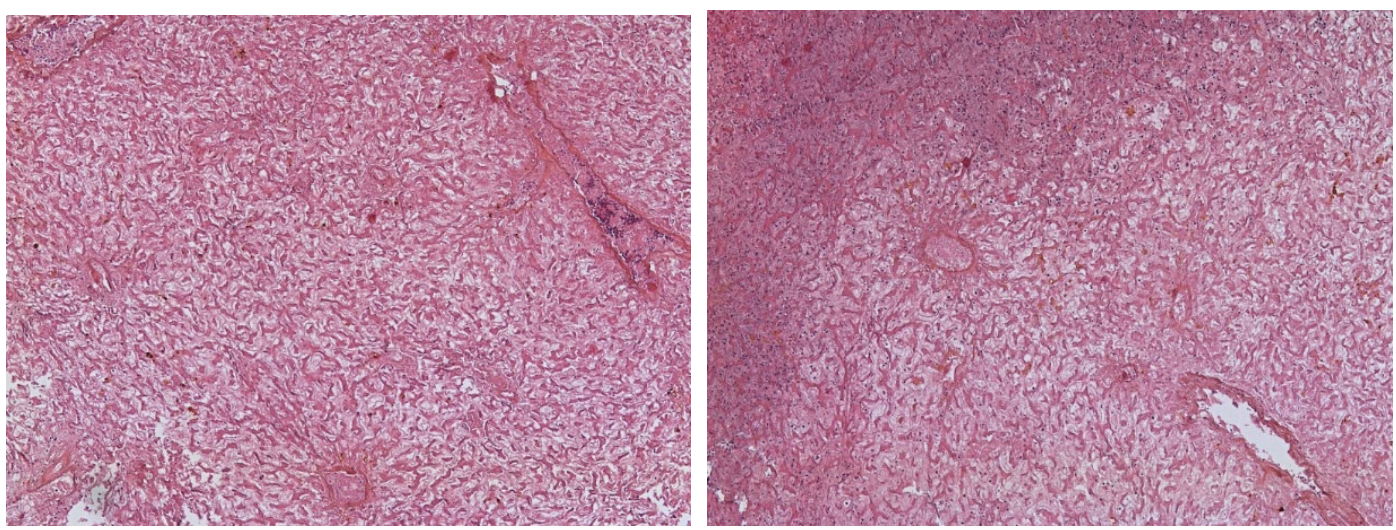

Figure 3: Histopathological findings revealed an heterotopic necrosed liver nodule. 
Citation: Rizzo R, Rousseau V, Berteloot L, Barbet P, Toubiana J. (2021) Ectopic Liver Nodule in an Infant with Pyloric Stenosis Presentation: First Detailed Case Report of Laparoscopic Resection in a Pediatric Patient. Ann Case Report 6: 751. DOI: 10.29011/2574-7754.100751.
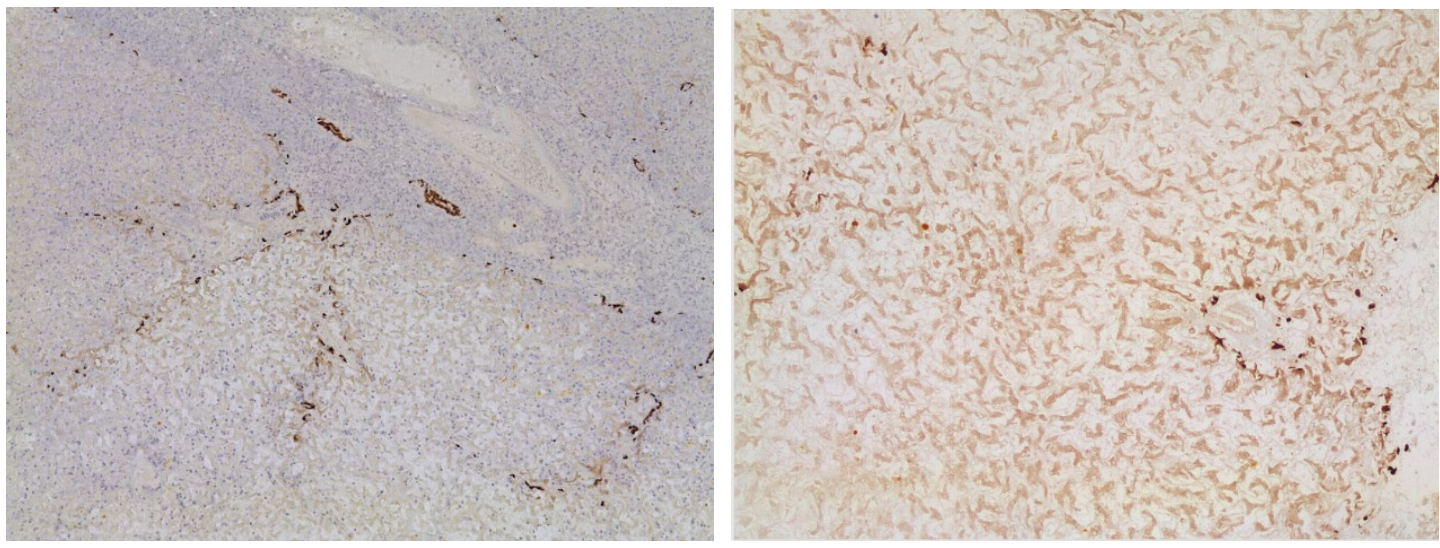

Figure 4: Histopathological findings revealed an heterotopic necrosed liver nodule. with centrals veins of hepatic lobule and biliary ducts.

\section{Discussion}

Ectopic liver and accessory liver lobes have been reported to be a rare clinical entities which generally are of no clinical importance [1-3]. However, development of hepatocellular carcinoma (HCC) [17,18], compression of adjacent structure due to a mass effect and torsion have been reported $[19,20]$.They are frequently described in the vicinity of liver in abdominal cavity (gallbladder, hepatic ligaments, diaphragm) [13-16] or in thoracic cavity [4-6], and are often associated with congenital diaphragmatic hernia, due to a migration of abdominal organs in the thorax [812].Often there isn't a vascular connection to the mother liver, and they should be vascularized by the umbilical artery, which explain the necrotic appearance due to circulatory reversal at birth in our patient and the inflammatory changes with adhesions and pyloric stenosis presentation.Most reports of ectopic liver cases indicate normal microscopic examination finding, and $\mathrm{HCC}$ in ectopic livers was no reported in pediatric patients.

Diagnostic work-up includes ultrasound study, contrastenhanced barium-meal, CT-scan or MRI-scan. The differential diagnosis includes pancreatic cyst or pseudocyst, choledocal cyst, gastric or duodenal duplication cyst, hypertrophic pyloric stenosis, ovarian or mesenteric cysts, and adrenal hemorrhage [19]. Resection of the ectopic liver has been suggested as the treatment of choice. These can be achieved through an open or a minimally invasive approach [7]. There are few cases in pediatric literature, and to the best of our knowledge this is the first detailed case report of a laparoscopic resection of ectopic liver.

\section{Conclusion}

In conclusion, although incidental ectopic livers are rare and do not have clinical importance in infants, they should appear with various presentation depending on where they develop. Laparoscopy resection represent a safe and effective approach even in infants, and microscopic examination should be carried out to exclude pathological changes.

\section{References}

1. Collan Y, Hakkiluoto A, Hästbacka J. (1978) Ectopic liver. In Annales Chirurgiae et Gynaecologiae 67: 27-29.

2. Zonca P, Martinek L, Ihnat P, Fleege J. (2013) Ectopic liver: different manifestations, one solution. World Journal of Gastroenterology: WJG, 19: 6485.

3. Watanabe M, Matsura T, Takatori Y, Ueki K, Kobatake T, et al. (1989) Five cases of ectopic liver and a case of accessory lobe of the liver. Endoscopy, 21: 39-42.

4. JimenezAR, Hayward, RH. (1971). Ectopic liver: a cause of esophageal obstruction. The Annals of thoracic surgery, 12(3), 300-304.

5. Iber T, Rintala R. (1999) Intrapulmonary ectopic liver. Journal of pediatric surgery, 34: 1425-1426.

6. Babu R, Van der Avoirt A. (2001) Ectopic intrathoracic liver. Pediatric surgery international, $17:$ 461-462.

7. Algin C, Yaylak F, Olgun EG, Caglikulekci M. (2008) Laparoscopic removal of an incidental ectopic liver: short report of a case. Case reports in gastroenterology, 2: 134-137.

8. Bedii Salman A. (2002) Left-sided congenital diaphragmatic hernia associated with intrathoracic ectopic liver lobule. European journal of cardio-thoracic surgery, 21: 558-560.

9. Arafah M, Boqari DT, Alsaad KO. (2011) Left-sided congenital diaphragmatic hernia with multiple congenital cardiac anomalies, hernia sac, and microscopic hepatic heterotopia: a case report. Pathology research international.

10. Patel RV, Wadhwani V, Wyatt-Ashmead J, Abel RM. (2013) Hepatic heterotopia in congenital diaphragmatic anomaly.

11. Loo CK, Pereira TN, Ramm GA. (2015) Case report: fetal bilateral diaphragmatic agenesis, ectopic liver and abnormal pancreas. Fetal and pediatric pathology, 34: 216-222. 
Citation: Rizzo R, Rousseau V, Berteloot L, Barbet P, Toubiana J. (2021) Ectopic Liver Nodule in an Infant with Pyloric Stenosis Presentation: First Detailed Case Report of Laparoscopic Resection in a Pediatric Patient. Ann Case Report 6: 751. DOI: 10.29011/2574-7754.100751.

12. Mito K, Amano Y, Oshiro H, Matsubara D, Fukushima N, et al. (2019) Liver heterotopia associated with congenital diaphragmatic hernia: Two case reports and a review of the literature. Medicine, 98.

13. Haddad EL, M. Y, Currie MY, Honeyman M. (1985) Pyloric obstruction by ectopic liver tissue. British journal of surgery, 72 .

14. Bruce J, Afshani E, Karp MP, Jewett TC. (1988) Omphalocele with pyloroduodenal obstruction by extrinsic hepatic compression: A case report. Journal of pediatric surgery, 23: 1018-1020.

15. Matley PJ, Rode H, Cywes S. (1989) Portal vein obstruction by ectopic liver tissue. Journal of pediatric surgery, 24: 1163-1164.

16. Merve A, Scheimberg I. (2014) Ectopic liver tissue in the kidney: case report and literature review. Pediatric and Developmental Pathology, 17: 382-385.
17. Kim KA, Park CM, Kim CH, Choi SY, Park SW, et al. (2003). Hepatocellular carcinoma in an ectopic liver: CT findings. European radiology, 13: L45-L47.

18. Caygill CP, Gatenby PA. (2004) Ectopic liver and hepatocarcinogenesis. European journal of gastroenterology \& hepatology, 16: 727-729.

19. Zonca P, Martinek L, Innat P, Fleege J. (2013). Ectopic liver: different manifestations, one solution. World Journal of Gastroenterology: WJG, 19: 6485.

20. Elsayes HB, Elzein MA, Razik AMA, Olude IO. (2005). Torsion of an ectopic liver in a young child. Journal of pediatric surgery, 40: E55-E58. 